\title{
A novel class 1 integron array carrying blaviM-2 genes and a new insertion sequence in a Pseudomonas aeruginosa strain isolated from a Spanish hospital
}

Pseudomonas aeruginosa is a pathogen commonly implicated in nosocomial infections. Carbapenems are an effective treatment option, but $P$. aeruginosa resistant to these agents are increasingly reported. The zinc-dependent metallo- $\beta$ lactamases (MBLs) are one of the most clinically important enzymes that hydrolyse carbapenems, penicillins and extended-spectrum cephalosporins, but not aztreonam (Walsh et al., 2005). Their activity is inhibited by the effect of metal chelators such as EDTA. The MBLs most frequently detected worldwide are the IMP and VIM types, which have been reported within genetic elements such as integrons (Walsh et al., 2005; Partridge et al., 2009). Integrons have the ability to capture, integrate and express gene cassettes involved in the resistance to different antimicrobial families (e.g. $\beta$-lactams, carbapenems and aminoglycosides) (Partridge et al., 2009). This facilitates the dissemination and co-selection of multiresistant $P$. aeruginosa strains and limits the therapeutic options (Bonomo \& Szabo, 2006).

$P$. aeruginosa strain W37 was recovered from a urinary sample in a Spanish hospital in 2007. Susceptibility testing was performed by the disc-diffusion method (CLSI, 2010). This strain showed resistance to imipenem, meropenem, ticarcillin, ceftriaxone, cefotaxime, gentamicin, tobramycin and sulfonamides; intermediate resistance to cefepime, aztreonam and ciprofloxacin; and susceptibility to ceftazidime, amikacin and colistin. The MICs of imipenem (IPM) and meropenem (MEM), determined by the agar dilution method (CLSI, 2010), were $>256$ and $64 \mathrm{mg} \mathrm{l}^{-1}$, respectively. The $\mathrm{MBL}$ Etest ( $\mathrm{AB}$ bioMérieux) and the

The GenBank accession number for the nucleotide sequence of the novel class 1 integron array determined in this study is GU354325. double-disc (IPM/0.5 M EDTA/MEM)

(Lee et al., 2001) methods proved an MBLpositive phenotype in this strain.

Multilocus sequence typing (MLST) showed in $P$. aeruginosa W37 a new allelic combination of the seven sequenced housekeeping genes (acsA6, aroE5, guaA6, mutL5, nuoD4, ppsA94, trpE7) that was registered and named ST973 in the MLST database (http://pubmlst.org/paeruginosa/) (Curran et al., 2004). This sequence type is a single-locus variant of ST641 and no clonal complex is yet described (Nemec et al., 2010).

MBL genes were detected and characterized by multiplex-PCR and subsequent sequencing (Ellington et al., 2007). The presence of class 1 and 2 integrons was determined by PCR, using primers targeting genes in the integron conserved segments (intI1, intI2 and $q a c E \Delta 1+$ sul1). Integron variable regions were analysed by PCR mapping and sequencing (Sáenz et al., 2004).

$P$. aeruginosa $\mathrm{W} 37$ harboured the $b{ } a_{\mathrm{VIM}-2}$ gene and two class 1 integrons. One of these integrons contained only a $b l a_{\mathrm{VIM}-2}$ gene cassette in its variable region, but the other one had a variable region of 5429 bp that included $b l_{a_{\mathrm{VIM}-2}}+\operatorname{aac}\left(6^{\prime}\right)$ -

$I b^{\prime}+\operatorname{aadAl}$ gene cassettes followed by a new open reading frame (ORF) and another $b l a_{\mathrm{VIM}-2}$ gene cassette (Fig. 1). The presence of two copies of the $b l a_{\mathrm{VIM}-2}$ gene is remarkable in this last integron. The $a a c\left(6^{\prime}\right)-I b^{\prime}$ gene encodes the $\mathrm{AAC}\left(6^{\prime}\right)-\mathrm{Ib}^{\prime}$ aminoglycoside acetyltransferase, which has an amino acid substitution

(Leu119 $\rightarrow$ Ser) with respect to AAC(6' $)-\mathrm{Ib}$, and confers resistance to gentamicin, tobramycin, kanamycin and netilmicin, a typical phenotype of an AAC(6')-II enzyme (Lambert et al., 1994).

The new ORF (1059 bp) encoded a putative transposase of 352 amino acids which is $62 \%$ similar to the IS 1618 transposase. This ORF was part of a new IS of $1216 \mathrm{bp}$, designated ISPa34 by IS Finder (http://www-is.biotoul.fr/). ISPa34 belongs to the IS110 family and IS1111 group, and it was inserted into the attC of the aadA1 gene cassette, whose mobilization could be affected. According to the IS110 family characteristics, no direct target repeats are created by ISPa34 (Mahillon \& Chandler, 1998).

The nucleotide sequence of the novel class 1 integron array determined in this study was deposited in the GenBank database with the accession number GU354325.

Several studies have described class 1 integrons containing the $b l a_{\mathrm{VIM}-2}$ gene cassette (Walsh et al., 2005; Santos et al., 2010; Samuelsen et al., 2010; Hammami et al., 2010), but to our knowledge, this is the first report of the double detection of $b l a_{\mathrm{VIM}-2}$ gene cassettes in the variable region of the same integron in $P$. aeruginosa. In addition, the presence of a new insertion sequence in the surrounding environment could be implicated in the mobilization of these gene cassettes.

The polymorphisms of the promoter $(\mathrm{Pc})$ responsible for the expression of inserted gene cassettes were characterized by PCR and sequencing in the two class 1 integrons of strain W37. The Pc hybrid 1 (PcH1) was detected in both integrons, characterized by the TGGACA and TAAACT sequences at the -35 and -10 hexamer positions, respectively. An in silico study has previously described (Jové et al., 2010) that the $\mathrm{PcH} 1$ variant is associated with weak expression of gene cassettes, and the resulting integrase with high excision activity, which favours the capacity for rearrangement of gene cassettes, in order to place the required gene cassette closer to PcH1.

The location of the class 1 integrons was studied by independent genomic DNA digestions with the nuclease $\mathrm{S} 1$ (8 $\mathrm{U}$ per plug) and the endonucleases I-CeuI and 


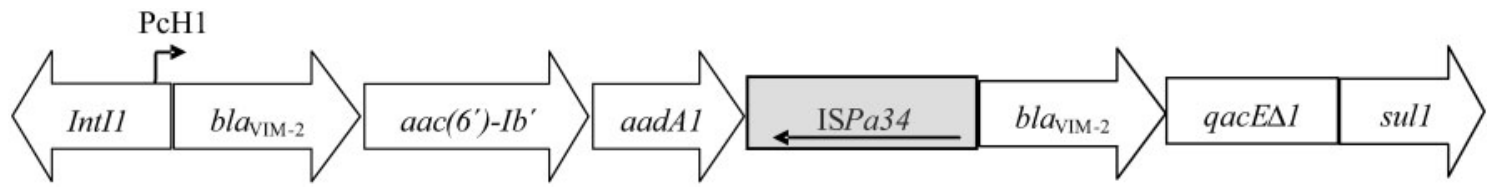

Fig. 1. Structure of the new class 1 integron of $P$. aeruginosa W37 (GenBank accession number GU354325).

SpeI (10 U per plug) (New England

Biolabs), and subsequent PFGE separations. Bacterial DNA embedded in agarose plugs was prepared as described by Kaufmann (1998). The PFGE conditions used were as follows: pulse time ranging from $5 \mathrm{~s}$ to $45 \mathrm{~s}$ for $16 \mathrm{~h}$ after nuclease $\mathrm{S} 1$ digestion, from $50 \mathrm{~s}$ to $90 \mathrm{~s}$ for $22 \mathrm{~h}$ after I-CeuI digestion, and two ramps were used after SpeI digestion, from $5 \mathrm{~s}$ to $15 \mathrm{~s}$ for $10 \mathrm{~h}$ and from $15 \mathrm{~s}$ to $45 \mathrm{~s}$ for another $10 \mathrm{~h}$. All gels were run at $6 \mathrm{~V} \mathrm{~cm}^{-2}$ and at $14{ }^{\circ} \mathrm{C}$. Digested PFGE gels were analysed by Southern blotting and hybridization using $b l a_{\mathrm{VIM}-2}$, intI1, ISPa34 and $16 \mathrm{~S}$ rRNA gene probes. The $b l_{\mathrm{VIM}-2}$ and intI1 genes hybridized in two bands with sizes between 97 and $145.4 \mathrm{~kb}$ in the SpeI-PFGE gel. DNA digestion with I-CeuI showed that the $b l a_{\mathrm{VIM}-2}$, intI1, ISPa34 and 16S rRNA probes hybridized only with chromosomal DNA. A DNA plasmid extraction and subsequent hybridization was performed and this also confirmed that the integron is chromosomally located.

In summary, a novel class 1 integron that contains two copies of the $b l a_{\mathrm{VIM}-2}$ gene and a new insertion sequence ISPa34 is reported. The accumulation of genes encoding MBL in $P$. aeruginosa strains is worrisome, especially when these structures could be mobilized by plasmids or transposons and transferred to other bacteria.

\section{Acknowledgements}

We thank Patricia Siguier for analysing the new ISPa34 (http://www-is.biotoul.fr/). The study did not receive financial support from third parties. M. de Toro has a pre-doctoral fellowship from the Ministerio de Ciencia e Innovación, Instituto de Salud Carlos III, Spain (grant number FI08/00506). V. Estepa has a pre-doctoral fellowship from the Universidad de La Rioja, Spain (grant number FPI-UR-09/16599009). Part of this study was presented at the XIV SEIMC Congress (Barcelona, Spain, 19-22 May 2010).

\section{Beatriz Rojo-Bezares, ${ }^{1}$ \\ Vanesa Estepa, ${ }^{2}$ María de Toro, ${ }^{1,2}$ Esther Undabeitia, ${ }^{3}$ Inés Olarte, ${ }^{3}$ Carmen Torres $^{1,2}$ and Yolanda Sáenz ${ }^{1}$}

${ }^{1}$ Área de Microbiología Molecular, Centro de Investigación Biomédica de La Rioja (CIBIR), Logroño, Spain

${ }^{2}$ Área de Bioquímica y Biología Molecular, Departamento de Agricultura y Alimentación, Universidad de La Rioja, Logroño, Spain

${ }^{3}$ Laboratorio de Microbiología, Hospital San Pedro, Logroño, Spain

Correspondence: Yolanda Sáenz

(ysaenz@riojasalud.es)

Bonomo, R. A. \& Szabo, D. (2006). Mechanisms of multidrug resistance in Acinetobacter species and Pseudomonas aeruginosa. Clin Infect Dis $\mathbf{4 3}$ (Suppl. 2), S49-S56.

CLSI (2010). Performance Standards for Antimicrobial Susceptibility Testing, 20th International Supplement M100-S20. Wayne,

PA: Clinical and Laboratory Standards Institute.

Curran, B., Jonas, D., Grundmann, H., Pitt, T. \& Dowson, C. G. (2004). Development of a multilocus sequence typing scheme for the opportunistic pathogen Pseudomonas aeruginosa. J Clin Microbiol 42, 5644-5649.

Ellington, M. J., Kistler, J., Livermore, D. M. \& Woodford, N. (2007). Multiplex PCR for rapid detection of genes encoding acquired metallobeta-lactamases. J Antimicrob Chemother 59, 321-322.

Hammami, S., Gautier, V., Ghozzi, R., Da Costa, A., Ben-Redjeb, S. \& Arlet, G. (2010). Diversity in VIM-2-encoding class 1 integrons and occasional bla $a_{\mathrm{SHV} 2 \mathrm{a}}$ carriage in isolates of a persistent, multidrug-resistant Pseudomonas aeruginosa clone from Tunis. Clin Microbiol Infect 16, 189-193.

Jové, T., Da Re, S., Denis, F., Mazel, D. \& Ploy, M. C. (2010). Inverse correlation between promoter strength and excision activity in class 1 integrons. PLoS Genet 6, e1000793.

Kaufmann, M. E. (1998). Pulsed-field gel electrophoresis. Methods Mol Med 15, 33-50.

Lambert, T., Ploy, M. C. \& Courvalin, P. (1994). A spontaneous point mutation in the aac $\left(6^{\prime}\right)$ $\mathrm{Ib}^{\prime}$ gene results in altered substrate specificity of aminoglycoside $6^{\prime}$ - $N$-acetyltransferase of a Pseudomonas fluorescens strain. FEMS Microbiol Lett 115, 297-304.

Lee, K., Chong, Y., Shin, H. B., Kim, Y. A., Yong, D. \& Yum, J. H. (2001). Modified Hodge and EDTAdisk synergy tests to screen metallo-betalactamase-producing strains of Pseudomonas and Acinetobacter species. Clin Microbiol Infect 7, 8891.

Mahillon, J. \& Chandler, M. (1998). Insertion sequences. Microbiol Mol Biol Rev 62, 725-774.

Nemec, A., Krizova, L., Maixnerova, M. \&

Musilek, M. (2010). Multidrug-resistant epidemic clones among bloodstream isolates of Pseudomonas aeruginosa in the Czech Republic. Res Microbiol 161, 234-242.

Partridge, S. R., Tsafnat, G., Coiera, E. \& Iredell, J. R. (2009). Gene cassettes and cassette arrays in mobile resistance integrons. FEMS Microbiol Rev 33, 757-784.

Sáenz, Y., Briñas, L., Domínguez, E., Ruiz, J., Zarazaga, M., Vila, J. \& Torres, C. (2004).

Mechanisms of resistance in multiple-antibioticresistant Escherichia coli strains of human, animal, and food origins. Antimicrob Agents Chemother 48, 3996-4001.

Samuelsen, Ø., Toleman, M. A., Sundsfjord, A., Rydberg, J., Leegaard, T. M., Walder, M., Lia, A., Ranheim, T. E., Rajendra, Y. \& other authors (2010). Molecular epidemiology of metallobeta-lactamase-producing Pseudomonas aeruginosa isolates from Norway and Sweden shows import of international clones and local clonal expansion. Antimicrob Agents Chemother 54, 346-352.

Santos, C., Caetano, T., Ferreira, S. \& Mendo, S. (2010). Tn5090-like class 1 integron carrying bla $a_{\mathrm{VIM}-2}$ in a Pseudomonas putida strain from Portugal. Clin Microbiol Infect 16, 1558-1561.

Walsh, T. R., Toleman, M. A., Poirel, L. \& Nordmann, P. (2005). Metallo-beta-lactamases: the quiet before the storm? Clin Microbiol Rev 18, 306-325. 